\title{
JANJÃO, UM PATRIMÔNIO DA NOSSA MEMÓRIA
}

\author{
Benedito Lima de Toledo
}

$\frac{254}{\text { ì }}$

O professor Antonio Luiz Dias de Andrade, Janjão, como todos o conheciam, foi aluno da FAUUSP e, posteriormente, professor do Departamento de História da Arquitetura e Estética do Projeto. Desde sua época de estudante interessou-se profundamente pela preservação de bens culturais. Foi diretor regional do Instituto de Patrimônio Histórico e Artístico Nacional (IPHAN). Sua dissertação de mestrado baseou-se em estudo muito original sobre técnicas construtivas no Vale do Paraíba e seu doutorado voltou-se especificamente para os conceitos fundamentais que regem a proteçāo do patrimônio histórico.

O presente documento refere-se a uma proposta feita ao IPHAN sobre preservação de uma capela rural em Santana do Parnaíba. Trata-se de um exemplar típico de arquitetura popular que não pode ser considerado como excepcional. Todavia, tem grande significado social. Arquitetura popular não pode ser confundida com arquitetura suburbana, nem de periferia. É, antes, manifestação de uma cultura que envolve convicções de uma determinada comunidade. Se não tem grande valor material, nem por isso deixa de ter representatividade. Foi o que afirmaram personalidades como Mário de Andrade e Lúcio Costa. Tal princípio levou arquitetos portugueses a realizar o famoso Inquérito de Arquitetura Popular em Portugal.

Em seu texto, Antonio Luiz coloca esse problema: "Pequenas capelas são encontradas em todo interior do estado, atestam tradições antigas, testemunham o modo de vida da população rural." Esses bens culturais são ignorados pelos órgãos de proteção do patrimônio, como testemunha Antonio Luiz em seu texto "(...) mas, persiste o menosprezo pelas pequenas construções rústicas, anônimas, palco de nenhum episódio memorável e, tampouco, fruto de algum gênero artistico"

A proposta apresenta grande atualidade e comparece em texto conciso e de grande densidade. É acompanhada de uma página em que vemos uma manifestação do invulgar talento de desenhista de seu autor, que sempre fez de seu desenho um poderoso instrumento de análise. Aí vemos planta de situação, planta de capela, perspectiva desta e uma visão do sítio onde se encontra, ficando bem clara a natureza do bem cultural em questão.

Dessa forma, a proposta de preservação da modesta Capela de Santo Antônio, no bairro do Suru é, na verdade, mais que isso, é uma proposição que representa uma contribuição à revisão do próprio conceito de preservação dos bens culturais. 
Parecer sobre o tombamento da Capela Santo Antonio. Bairro do Suru, Santana do Parnaíba

\author{
Senhora Coordenadora - SPHAN
}

A pequena Capela de Santo Antônio, no Bairro do Suru, no município de Santana do Parnaiba, jamais poderia vir a ser equiparada às manifestações mais significativas do patrimônio cultural de nosso país, sequer do Estado, a prevalecer os juízos de valor que via de regra têm sido avocados para apreciar o mérito e as qualidades do legado cultural do passado.

Trata-se de um pequenino templo, extremamente singelo, construído em época relativamente recente, provavelmente no princípio deste século. Destituída de valores maiores, todavia, a capelinha está a exigir as nossas atenções, em face das ameaças decorrentes do desejo da paróquia em construir no local uma nova igreja.

Acostumados a atribuir importância apenas àqueles bens que por "sua vinculação a fatos memoráveis da história do Brasil, quer por seu excepcional valor arqueológico ou etnográfico, bibliográfico ou artístico" sejam merecedores da tutela do poder público.

Temos estado pouco atentos às expressões da cultura popular, desmerecendo o pensamento de Mário de Andrade - autor, inclusive, do anteprojeto de lei que gerou o aludido decreto-lei, que cuida da proteção dos monumentos brasileiros - e para quem, além das obras maiores, deveriam igualmente ser conservados "a arquitetura popular, cruzeiros, capelas e cruzes de beira-de-estrada" obras estas, ainda segundo suas palavras, "sob o ponto de vista de arte pura não são dignas de admiraçāo, nāo orgulham a um país nem celebrizam a autor delas"

Pequenas capelas são encontradas em todo o interior do estado; atestam tradiçōes antigas, testemunham o modo de vida da população rural.

Tão mais importantes se mostram hoje tais remanescentes quando observamos os processos de mudança que revertem os hábitos e as tradições que compunham os quadros de vida do mundo rural.

A frágil cultura do homem rural, sustenta-se, segundo Antônio Cândido de Mello e Sousa, em seu clássico estudo Os parceiros do rio Bonito, no regime de posse de terra, no auxílio vicinal, na disponibilidade de terrenos e na pequena margem de lazer, "tornada possivel numa cultura organizada em torno de padrões mínimos" não foi capaz de resistir à expansão do mundo urbano e industrial, deixando-nos raros traços da antiga ordem.

A população, distribuida e assentada nos bairros rurais, solidariza-se nos eventos religiosos, nas rezas caseiras, nas festas promovidas em cumprimento de promessas e naquelas organizadas em devoção aos santos padroeiros, de cujas interferências, segundo as palavras de um outro importante estudioso de nosso universo rural, Emílio Williens, "dependem as colheitas e, portanto, o bem-estar material do povo"

O espaço rural tornou-se, assim, povoado de pequenas capelas: algumas toscas construções de quatro esteios cobertos de palha, erguidas em devoção a algum santo, 


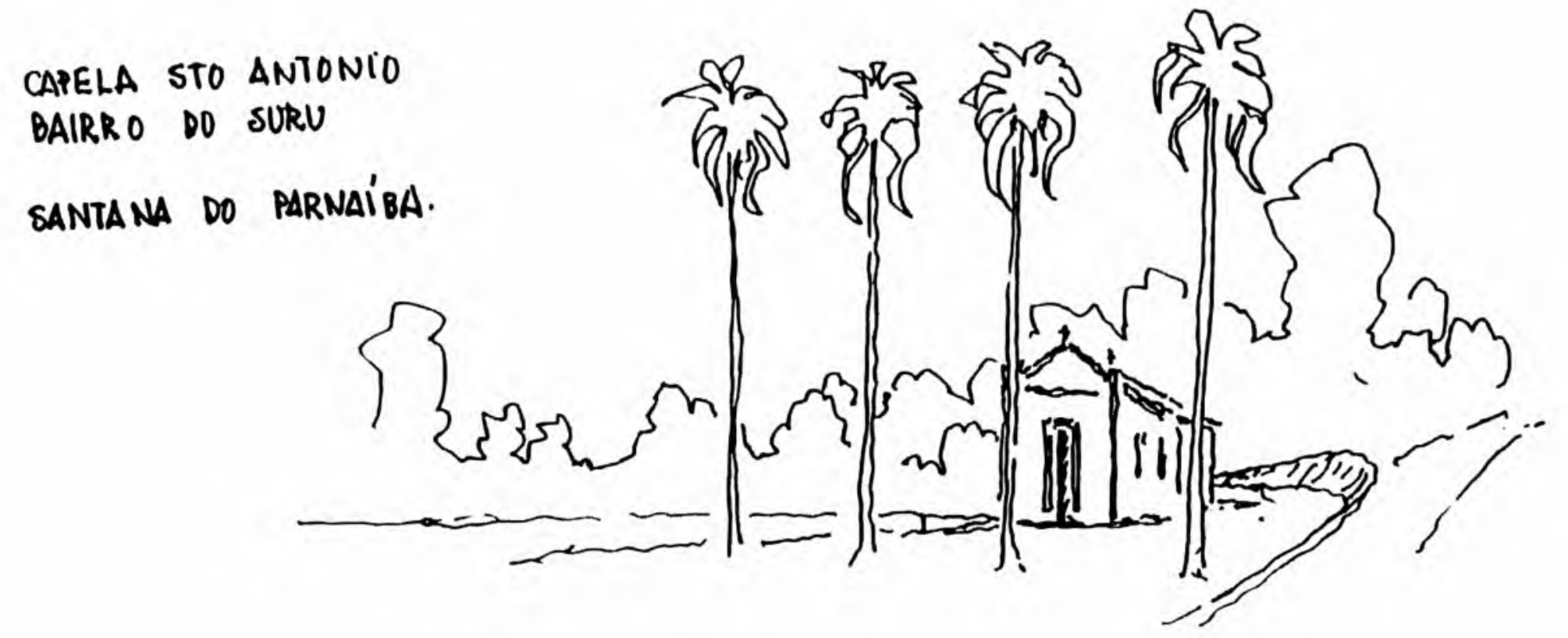

$\frac{256}{\dot{\check{c}}}$

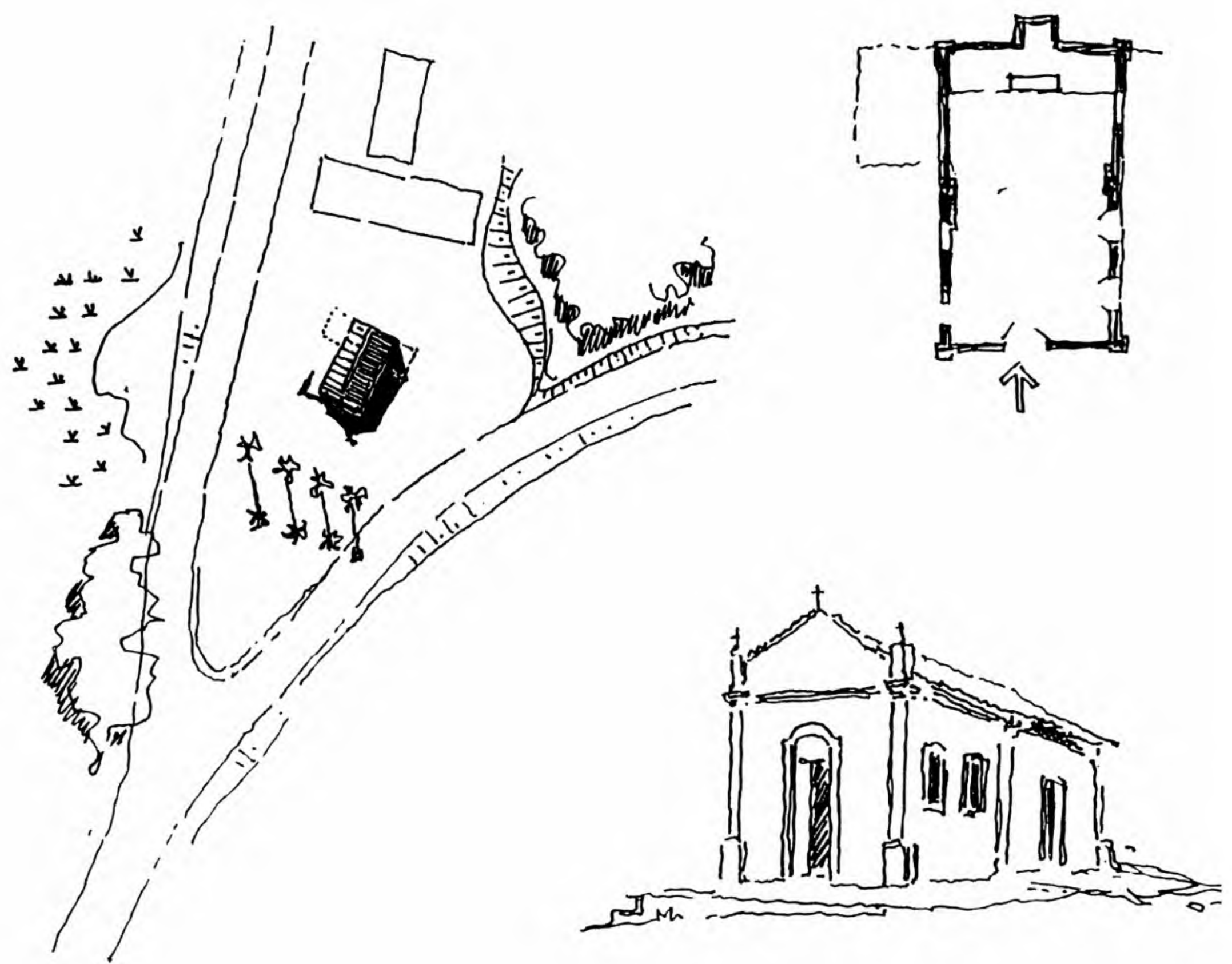


onde se rezam novenas e diante das quais os transeuntes tiram o chapéu e fazem o sinal da cruz. Outras são melhor construídas, as mais antigas conservam a taipa de pilão, as mais novas empregam alvenaria. Algumas possuem nave, capela-mor e sacristia e não deixaram os seus construtores desprovido o frontispício de singelos ornatos. Voltam-se, em regra, para amplos terreiros fronteiros, os locais das festas e dos eventos religiosos.

Hoje, num país com aproximadamente $80 \%$ de sua população residindo nas áreas urbanas, nāo é de se estranhar grandes mudanças no meio rural e o desaparecimento das formas tradicionais de organização do espaço.

Áreas imensas foram incorporadas pelas grandes propriedades; algumas, abandonadas, incitam o movimento dos sem-terra e inúmeras vêm sendo invadidas pela expansão das periferias das grandes cidades. Nessas áreas ainda é possível depararmos com algum "resto esburacado que o acaso se esqueceu de destruir"

Jamais alguém cogitará de demolir a Igreja de São Francisco de Ouro Preto, como também tantos outros monumentos, tidos como as mais elevadas manifestações do espírito humano que acompanharam a nossa história, mas persiste o menosprezo pelas pequenas construções rústicas, anônimas, palco de nenhum episódio memorável e tampouco fruto de algum gênio artístico.

Obras simples, produzidas por mãos calejadas, incultas e deseducadas na arte de construir.

Obras que "não doem destruir"

São Paulo, 10 de setembro de 1996

Arquiteto Antonio Luiz Dias de Andrade 